\title{
Synergism in hyperhomocysteinemia and diabetes: role of PPAR gamma and tempol
}

\author{
Paras K Mishra, Neetu Tyagi, Utpal Sen, Irving G Joshua, Suresh C Tyagi*
}

\begin{abstract}
Background: Hyperhomocysteinemia (HHcy) and hyperglycemia cause diabetic cardiomyopathy by inducing oxidative stress and attenuating peroxisome proliferator- activated receptor (PPAR) gamma. However, their synergistic contribution is not clear.
\end{abstract}

Methods: Diabetic Akita (Ins2+/-) and hyperhomocysteinemic cystathionine beta synthase mutant (CBS+/-) were used for M-mode echocardiography at the age of four and twenty four weeks. The cardiac rings from WT, Akita and hybrid (Ins2+/-/CBS+/-) of Akita and CBS+/- were treated with different doses of acetylcholine (an endothelial dependent vasodilator). High performance liquid chromatography (HPLC) was performed for determining plasma homocysteine (Hcy) level in the above groups. Akita was treated with ciglitazone (CZ) - a PPAR gamma agonist and tempol-an anti-oxidant, separately and their effects on cardiac remodeling were assessed.

Results: At twenty four week, Akita mice were hyperglycemic and HHcy. They have increased end diastolic diameter (EDD). In their heart PPAR gamma, tissue inhibitor of metalloproteinase-4 (TIMP-4) and anti-oxidant thioredoxin were attenuated whereas matrix metalloproteinase (MMP)-9, TIMP-3 and NADPH oxidase 4 (NOX4) were induced. Interestingly, they showed synergism between HHcy and hyperglycemia for endothelial-myocyte (EM) uncoupling. Additionally, treatment with CZ alleviated MMP-9 activity and fibrosis, and improved EDD. On the other hand, treatment with tempol reversed cardiac remodeling in part by restoring the expressions of TIMP-3,-4, thioredoxin and MMP-9.

Conclusions: Endogenous homocysteine exacerbates diabetic cardiomyopathy by attenuating PPAR gamma and inducing E-M uncoupling leading to diastolic dysfunction. PPAR gamma agonist and tempol mitigates oxidative stress and ameliorates diastolic dysfunction in diabetes.

\section{Background}

Hyperhomocysteinemia (HHcy) is an independent cause of cardiovascular diseases [1,2]. In diabetes, plasma homocysteine level is elevated [3,4]. Both hyperglycemia and HHcy lead to diabetic cardiomyopathy, which is a leading cause of morbidity and mortality [5-9]. A positive correlation exits between plasma homocysteine (Hcy) and left ventricular hypertrophy (LVH) in diabetes [10]. A direct link between Hcy and cardiovascular diseases is evident from the fact that every $3 \mu \mathrm{M} / \mathrm{L}$ increase in Hcy level contributes to $10 \%$ increase in the risk of coronary heart disease and $20 \%$ more chances of stroke [11]. Hcy induces cardiac hypertrophy in rats [12,13] and instigates bradycardia [14,15]. Hcy engenders

\footnotetext{
* Correspondence: suresh.tyagi@louisville.edu

Department of Physiology \& Biophysics, School of Medicine, University of Louisville, Louisville, Kentucky-40202, USA
}

oxidative stress by generating reactive oxygen species (ROS) [16,17]. In diabetes, Hcy mediated generation of oxidative radicals induce matrix metalloproteinases (MMPs) and inhibit their tissue inhibitors (TIMPs) that result into extracellular matrix (ECM) remodeling $[18,19]$. Additionally, activation of MMPs degrades endothelial basement membrane [20] that connects endothelium to myocytes through ECM and adhesion molecules. The disruption of connection between endothelium (E) and myocytes (M) causes E-M uncoupling $[21,22]$ resulting into defective diastolic relaxation. There are evidences suggesting the effect of Hcy on hypertension [23], diabetes [4] and insulin resistance [24]. However, synergism between Hcy and hyperglycemia in diabetic cardiomyopathy is unclear.

The insulin2 mutant (Ins2+/-) Akita has been used as a genetic model for type1 diabetes. Due to heterozygous 
mutation in Insulin2 gene (located on chromosome 7), the proinsulin 2 is misfolded and cannot exocytose from pancreatic beta cells resulting into accumulation and ultimately death of beta cells. These mice are normoglycemic until the age of three week and blood glucose level shoots up constantly after three-four weeks reaching robust hyperglycemia at ten week. Akita has been used as a model system for diabetes [25]. On the other hand, cystathionine beta synthase mutant $(\mathrm{CBS}+/-)$ is widely used as a model system for HHcy. CBS gene is located on chromosome 17 and is required for metabolism of Hcy by transsulfuration pathway [26-29]. The double knock out of Akita and CBS+/- is not available. To investigate individual and synergistic effect of hyperglycemia and HHcy, we cross-bred Akita with CBS+/to obtain four types of offspring: Ins $2+/+/ \mathrm{CBS}+/+(\mathrm{WT})$; Ins $2+/-, \mathrm{CBS}+/+$ (Akita); Ins $2+/+/ \mathrm{CBS}+/-$ (CBS mutant) and Ins2+/-/CBS+/- (double knock out).

Glucose mediated oxidative stress is mitigated by peroxisome proliferator- activated receptors (PPARs). They are ligand-activated transcription factors that play pivotal role in regulation of genes involved in hyperglycemia, lipid metabolism, vascular tone and inflammation [30-32]. PPAR $\gamma$ contributes in ameliorating diabetic complications $[3,33,34]$. The PPAR $\gamma$ agonists modulate insulin resistant [33,34] and activated PPAR $\gamma$ inhibits MMP activation [35]. Interestingly, PPAR $\gamma$ cannot decrease plasma Hcy [18,36-38]. Nevertheless, it is attenuated by HHcy [39]. In a ventricular pressure overload model of mice, reduced expression of PPAR $\gamma$ causes left ventricular hypertrophy [40]. The PPAR $\gamma$ agonist (PGJ2) showed a competition for binding to PPAR $\gamma$ with Hcy [41] and ameliorates diabetic cardiac hypertrophy [42]. However, the independent and synergistic effect of Hcy and PPAR $\gamma$ in cardiac hypertrophy and matrix remodeling in diabetes is nebulous.

$\mathrm{HHcy}$ engenders oxidative stress by inducing reactive oxygen species (ROS) and enhances NADPH oxidase 4 (NOX4) [43]. ROS is attenuated by tempol, an anti-oxidant $[43,44]$. The use of anti-oxidant to mitigate the effect of oxidative stress is a promising approach for treating diabetic cardiomyopathy [45]. ROS also affects nitric oxide (NO) that in contact with superoxide generates highly reactive peroxynitrite $\left(\mathrm{ONOO}^{-}\right)$, which induces cascade of pathological signaling. Nitric oxide (NO) is a vasodilator and is considered as cardioprotective molecule that maintains E-M coupling. This study was designed to investigate association between Hcy and glucose in structural and functional remodeling of endocardium by defining their link to PPAR $\gamma$ and NO metabolism in diabetes. We hypothesize that E-M uncoupling in diabetes is due in part to increased level of homocysteine causing activation of latent MMP-9, attenuation of thioredoxin and TIMP-4 in response to antagonizing PPAR $\gamma$.

\section{Methods}

\section{Animal model}

Akita, CBS+/- and C57 BL/6J (WT) were procured from Jackson Laboratory (Bar Harbor, ME). To avoid gender specific complexity, only male mice were used for the experiments. They were housed in the animal care facility of University of Louisville and fed standard mouse chow diet. The animal room was maintained at $22-24^{\circ} \mathrm{C}$ with $12: 12$ hour light-dark cycle. At the end of experiments, animals were sacrificed following the protocol approved by Institutional Animal Care and Use Committee of University of Louisville. Further, animal care and use programs were carried out according to standard protocol and guidelines of National Institute of Health (NIH) and Guide for the Care and Use of Laboratory Animals (NIH Pub. No. 86-23, revised 1985) and regulation of Animal Welfare Act.

\section{Genotyping of Akita and CBS mutant mice}

DNA was extracted from the tail tip of mice at the age of six to eight weeks and was amplified by PCR using specific primer sequences. The primer sequence for Ins2 gene was designed from the region of exon 3 because Ins2 mutation in Akita disrupts Fnu $4 \mathrm{HI}$ site in the exon 3 of Ins 2 and digestion with $F n u 4 H$ did not change the size of PCR product from mutated allele $(280 \mathrm{bp})$, rather it decreased the size of the wild type allele to $140 \mathrm{bp}$. The primer sequences were forward: 5'TGC TGAT GCC CTG GCC TGCT 3'; reverse: 5' CAC ATA TGC ACA TG 3'. For CBS heterozygous mutation, primer sequences were designed from intron 3 flanking the region of neo insert in CBS gene [46]. The primer sequences were forward: 5' GCCTCTGTCTGCTAACCTA3'; reverse: 5' GAGGTCGACGG TATCGATA3'. The PCR product of CBS from wild type is $800 \mathrm{bp}$, while the disrupted/ mutant allele was $180 \mathrm{bp}$.

\section{Double knock out and treatment groups}

To obtain the double knock out of Akita and CBS+/- (Ins2 $+/-/ C B S+/-)$, female Akita were crossed with male CBS+/(2区: $1 \rrbracket)$. Four types of offspring were produced: WT, Akita, CBS+/- and double knock out (Ins2+/-/CBS+/-). At the age of twenty week, these offspring were treated with vehicle (normal drinking water), PPAR $\gamma$ agonist ciglitazone (CZ-Cal Biochem Corp, CA, USA) $-8 \mu \mathrm{g} / \mathrm{ml}$ and anti-oxidant tempol (Sigma Aldrich, USA)-10 mM/L for four weeks through drinking water. Both $\mathrm{CZ}$ and PPAR $\gamma$ bind at the micromolar range [31]. Assuming the total blood volume $2 \mathrm{ml}$ and daily drinking water intake $5 \mathrm{ml}$, the 8 $\mu \mathrm{g} / \mathrm{ml}$ of $\mathrm{CZ}$ in drinking water added into the blood $\sim 2$ $\mathrm{mg} \mathrm{CZ} / \mathrm{kg}$ body weight/day producing a blood concentration of $\sim 32 \mu \mathrm{M} / \mathrm{L}$, which was enough to saturate the 
binding sites of PPAR $\gamma$ [47]. To rule out the other effects of PPAR $\gamma$ agonist [48], food and water intake was measured every second day during the treatment. Additionally, liver was weighed at the end of experiments (data not shown) to confirm that there was no peroxisome proliferation and hepatotoxicity [49] after treatment with $\mathrm{CZ}$ as reported with other PPAR $\gamma$-agonists [50].

\section{Blood glucose measurement}

A glucometer with one-touch strip was used to measure the blood glucose level in $\mathrm{mg} / \mathrm{dL}$.

\section{HPLC for Hcy level measurement}

Blood drawn from the dorsal aorta of mice with the help of heparin rinsed syringe was collected in an Eppendorf tube on ice. It was immediately centrifuged at the rate of $5000 \mathrm{rpm}$ for $10 \mathrm{~min}$ at $4^{\circ} \mathrm{C}$. The clear plasma was collected and stored at $-80^{\circ} \mathrm{C}$ and used for HPLC. Hcy in the plasma samples was detected using a Shimadzu Class-VP 5.0 chromatograph (Shimadzu) as described previously [51].

\section{Echocardiography}

M-mode echocardiogram was obtained from a SONO5500 echocardiographic system equipped with a 12 $-\mathrm{MHz}$ phased- array transducer. The transducer was placed on the left hemithorax of mice so that echocardiogram could be taken from a short-axis view of the left ventricle at or just below the tip of the mitral-valve leaflet. Only those echocardiograms, which showed welldefined continuous interfaces of the septum and posterior wall, were collected and ventricle volume and axis lengths were determined.

Cardiac ring preparation and study of relaxation response Transverse sections of approximately 2-3 mm thickness that appeared as "doughnut" was prepared from left ventricle (LV) after removing the right ventricle. The heart was sectioned transmurally in such a manner that $\mathrm{LV}$ rings (cardiac ring) of even thickness could be obtained. The rings were immediately mounted on a polygraph in a tissue myobath containing physiological saline solution (PSS-118 mM NaCl, $4.7 \mathrm{mM} \mathrm{KCl,} 2.5$ $\mathrm{mM} \mathrm{CaCl} 2,1.2 \mathrm{KH}_{2} \mathrm{PO}_{4}, 1.2 \mathrm{MgSO}_{4}$, and 11.2 Dextrose) maintained at $37^{\circ} \mathrm{C}$. After stretching the ring, it was brought to the resting tension where $20 \mathrm{mM} \mathrm{CaCl}_{2}$ was applied. When the contraction was maximum, different doses of acetylcholine was added to myobath. Acetylcholine stimulates endothelial dependent contraction. To avoid the orientation dependent variation in contraction measurement, two measurements at the rotation of cardiac rings at $90^{\circ}$ was determined and average was used. The maximum contraction by $20 \mathrm{mM} \mathrm{CaCl}_{2}$ was taken as $100 \%$ contraction and percentage relaxation was calculated as a fraction of $100 \%$ contraction. Further, to avoid ischemia, the myobath was bubbled with a mixture of $95 \%$ oxygen and $5 \%$ carbon dioxide throughout the experiment and the experiment was completed within $40 \mathrm{~min}$ [52].

\section{RT-PCR}

The reverse-transcription polymerase chain reaction was performed after extracting RNA from left ventricle. The Promega RT-kit was used for reverse transcription following the method as described elsewhere [53]. The mRNA levels of PPAR $\gamma$, NOX4, Trx, MMP-2, -9 and GAPDH were determined by RT-PCR using following primers: Thioredoxin (Trx) sense: 5' TGGATCCATTTCCATCTGGT 3' antisense: 5' CCTTGTTAGCACCGGAGAAC 3', GAPDH sense: 5' TGAAGGTCG GTGTG AAC GGATTTGGC 3' antisense: 5' CATGTAGGCCATGAGGTCCACCAC3', MMP-2 sense: 5' GCACTCTGGAGCGAGGATAC 3' antisense: 5'GCCC TCCTAAGCCAGTCTCT3', MMP -9 sense: 5' AAGGCAAACCCTGTGTGTTC3' antisense: 5'GTGGTTC AGTT GTGGTGGTG3', NOX4 sense: 5' CCA GAA TGA GGA TCC CAG AA 3' antisense: 5' TGG AAC TTG GGT TCT TCC AG3', PPAR $\gamma$ sense: 5' ATGGCCATTGAGTGCCGAGTCTG3' antisense: 5'GGCTTTT GAGGAACTCCCTGGT CA3'. The PCR program for MMP-2,-9 and GAPDH was $94^{\circ} \mathrm{C}-2 \mathrm{~min},\left[94^{\circ} \mathrm{C}-30 \mathrm{sec}\right.$, $\left.57^{\circ} \mathrm{C}-30 \mathrm{sec}, 72^{\circ} \mathrm{C}-1 \mathrm{~min}\right] \mathrm{x} 30,72^{\circ} \mathrm{C}-2 \mathrm{~min}$. For $\operatorname{Tr} \mathrm{x}$ and Nox4, the PCR programs were $94^{\circ} \mathrm{C}-5 \mathrm{~min}$, $\left[94^{\circ} \mathrm{C}\right.$ $\left.40 \mathrm{sec}, 55^{\circ} \mathrm{C}-40 \mathrm{sec}, 72^{\circ} \mathrm{C}-1 \mathrm{~min}\right] \times 30,72^{\circ} \mathrm{C}-5 \mathrm{~min}$ and $94^{\circ} \mathrm{C}-2 \mathrm{~min},\left[94^{\circ} \mathrm{C}-1 \mathrm{~min}, 53^{\circ} \mathrm{C}-1 \mathrm{~min}, 72^{\circ} \mathrm{C}-1 \mathrm{~min}\right.$ ] $\times$ $30,72^{\circ} \mathrm{C}-5 \mathrm{~min}$, respectively.

\section{Protein extraction and Western Blotting}

The left ventricle from freshly extracted heart was homogenized in Ripa buffer (Boston BioProducts, Worcester, MA, USA) with proteinase inhibitor cocktail (Sigma, Saint Louis, MO, USA) and centrifuged at 5000 rpm for $5 \mathrm{~min}$ at $4^{\circ} \mathrm{C}$. The supernatant was collected. The concentration of proteins was estimated by Bradford method as described elsewhere [53]. The Western blotting was performed by following the same protocol as described earlier [53].

\section{Statistical analyses}

At least five mice were used from each group and data were presented as mean and standard deviation (SD). Student $\mathrm{t}$-test was used and a value of $\mathrm{p}<0.05$ was considered as significant.

\section{Results}

The comparison of blood glucose level of Akita and WT at four and twenty four weeks revealed that at four week both WT and Akita are normoglycemic. However, 
there was significant increase in the blood glucose level at twenty four week in Akita (Figure 1A). To investigate the effect of hyperglycemia on Hcy, plasma Hcy level was determined in the same groups of animals. Concurrent with the glucose level, there was significant elevation in Hcy level in twenty four week Akita (Figure 1B). To determine whether elevation of glucose and Hcy level had effect on the cardiac function, M-mode echocardiography was performed, which showed increase in end diastolic diameter (EDD) in twenty four week Akita (Figure 1C). Since both glucose and Hcy level was enhanced in Akita (Figure 1A, B), the independent and/ or synergistic effect of Hcy and glucose on cardiac dysfunction was determined by using double knock out (Ins2+/-/CBS+/-). The genotypes of the mutants were confirmed by PCR using Ins 2 and CBS specific primers (Figure 2). The double bands represent heterozygous mutation (Figure 2). The plasma Hcy level was determined in the mutants and compared with WT. Hcy level was significantly high in both $\mathrm{CBS}+/$ - and Ins2+/when compared with WT (Figure 3). Interestingly, in double knock out, Hcy level increased almost two-fold as compared to that of Akita. Notably, the elevation of Hcy level was significantly $(\mathrm{p}<0.05)$ higher in double knock out when compared to CBS+/- (Figure 3). The expression of PPAR $\gamma$, NOX- 4 and Trx was measured in all four groups (WT, Ins2+/-, CBS+/- and $\mathrm{CBS}+/$ //Ins2 $+/-)$. It revealed a significant increase in NOX-4, while decrease in PPAR $\gamma$ and $\operatorname{Trx}$ in all the three mutants $(\mathrm{CBS}+/-$, Ins2+/- and Ins2+/-/CBS+/-) (Figure 4).

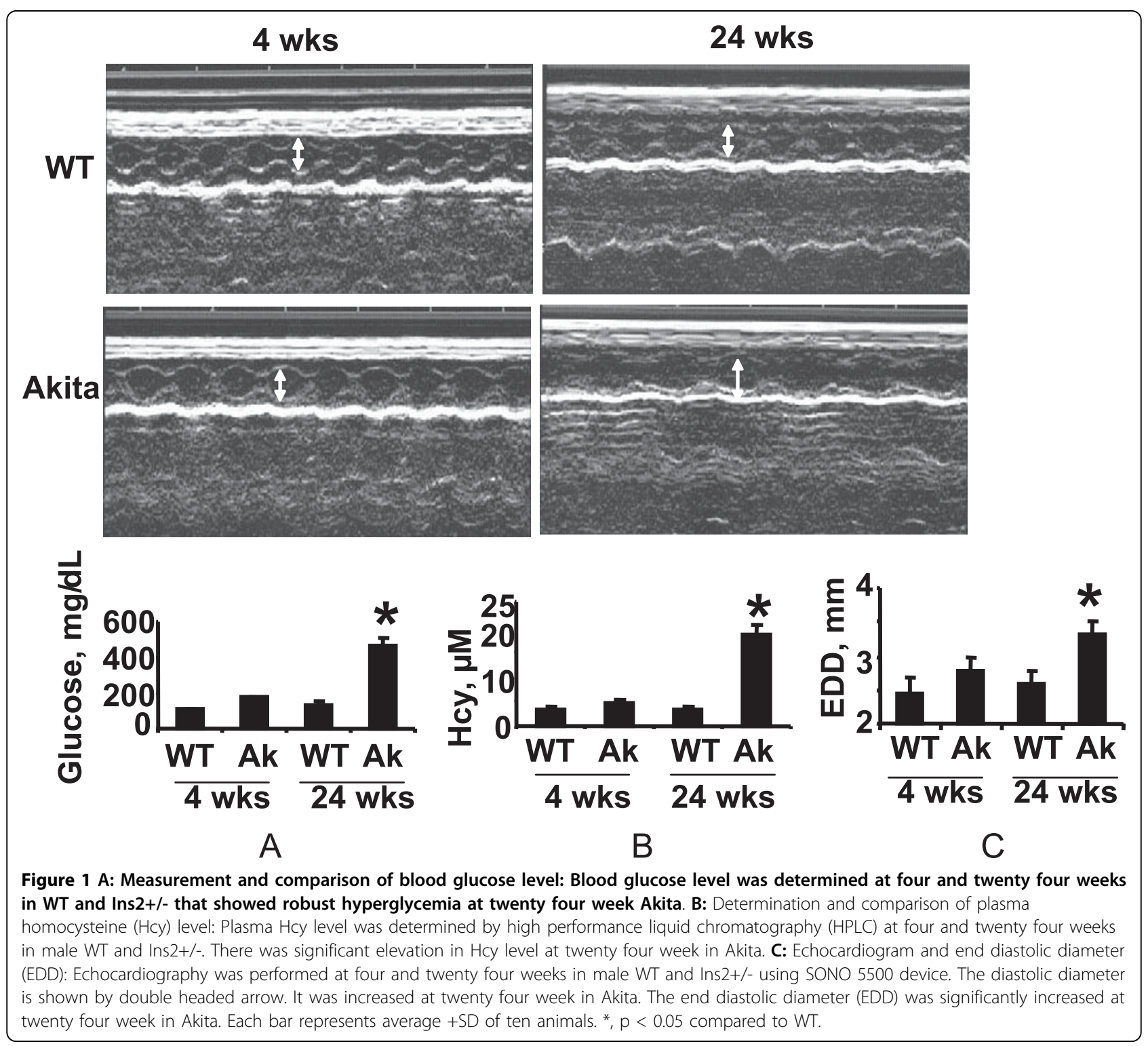




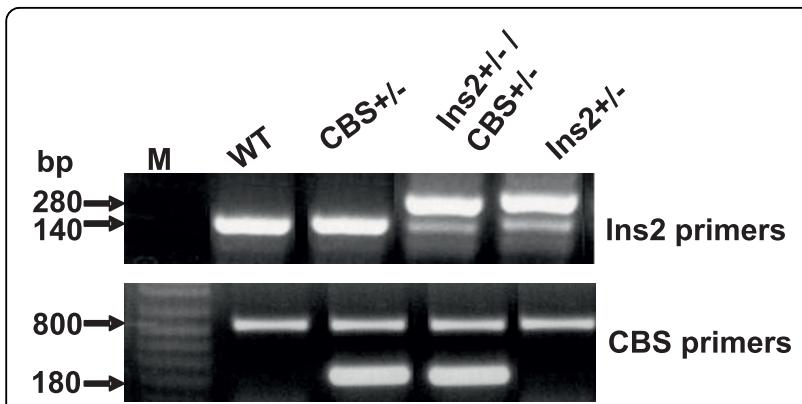

Figure 2 Genotyping of Ins2+/-, CBS +/- and Ins2+/-/CBS+/Two PCR products suggest the heterozygous mutation, while single band represents WT allele. In Ins $2+/-$ and CBS +/-, the double bands of specific PCR product confirmed the heterozygous mutation of Ins2 and CBS genes, respectively.

Further, there was significant up regulation of MMP-9 and down regulation of MMP-2 in CBS+/- (Figure 4). Remarkably, the total urinary protein concentration was increased in the above three mutants (Figure 5). To determine the E-M uncoupling, cardiac rings from the four groups were treated with different doses of acetylcholine after pre-constriction by $\mathrm{CaCl}_{2}$ and their rate of relaxation was measured (Figure 6A). There was a clear gradient decrease in the rate of relaxation in WT, CBS +/-, Ins2+/- and Ins2+/-/CBS+/- (Figure 6B).

To determine the role of PPAR $\gamma$ in diabetic cardiomyopathy, Akita was treated with CZ. The activity of MMP-9 was determined in WT and Akita with and without treatment with $\mathrm{CZ}$. There was up regulation of
MMP-9 activity in Akita. However, it was attenuated after treatment with CZ (Figure 7). The collagen deposition, which indicates fibrosis, was also decreased in Akita after treatment with CZ (Figure 8). The diastolic function is reflected through diastolic diameter. It was improved in CZ treated Akita (Figure 9). To determine the effect of oxidative stress on diabetic cardiomyopathy, Akita was treated with tempol, an anti-oxidant. The results showed mitigation of NOX-4 and enhancement of Trx level in tempol treated Akita (Figure 10). Additionally, MMP-9 and TIMP-3 were attenuated, while MMP-2 and TIMP-4 were induced in tempol treated Akita (Figure 10). Nevertheless, there was no change in the TIMP-1 expression (Figure 10).

\section{Discussion}

There are two insulin genes in mice: insulin 1 and insulin 2 . Insulin 2 is predominantly involved in glucose metabolism and is homologous to human insulin. Recent clinical data revealed that mutation in insulin 2 is a major cause of neonatal diabetes [54]. Therefore, insulin 2 mutant Akita mouse that resembles human hypoinsulinemia has been used for investigating the mechanism of diabetic cardiomyopathy. Hypoinsulinemia in later stage leads to insulin insensitivity- a feature of type 2 diabetes [55]. The four groups obtained by cross- breeding Ins $2+/$ - with $\mathrm{CBS}+$ /- provides insight into the independent and synergistic implications of HHcy and hyperglycemia on diabetic cardiomyopathy. The proinsulin maturation and exportation to cytoplasm
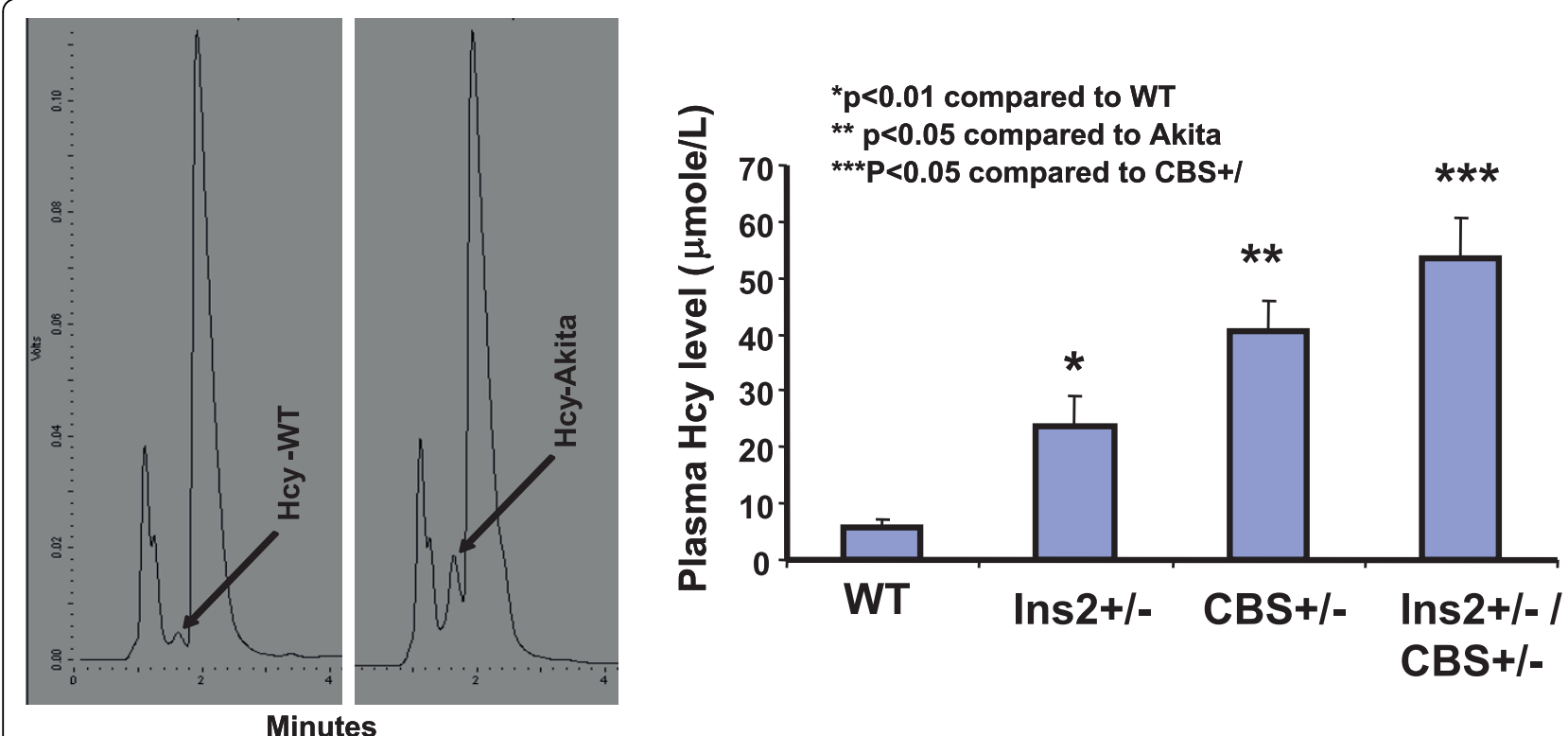

Figure 3 Determination and comparison of plasma Hcy level by HPLC: The peak of plasma Hcy was shown in WT and Ins2+/-. Hcy level was determined and compared among WT, Ins2+/-, CBS +/- and Ins2+/-/CBS+/-. Each bar represents average +SD from six animals. *, $p<0.05$ compared to WT; ${ }^{* *} \mathrm{p}<0.05$ compared to Ins2+/-, and ${ }^{* * *}, \mathrm{p}<0.05$ compared to CBS+/-. 


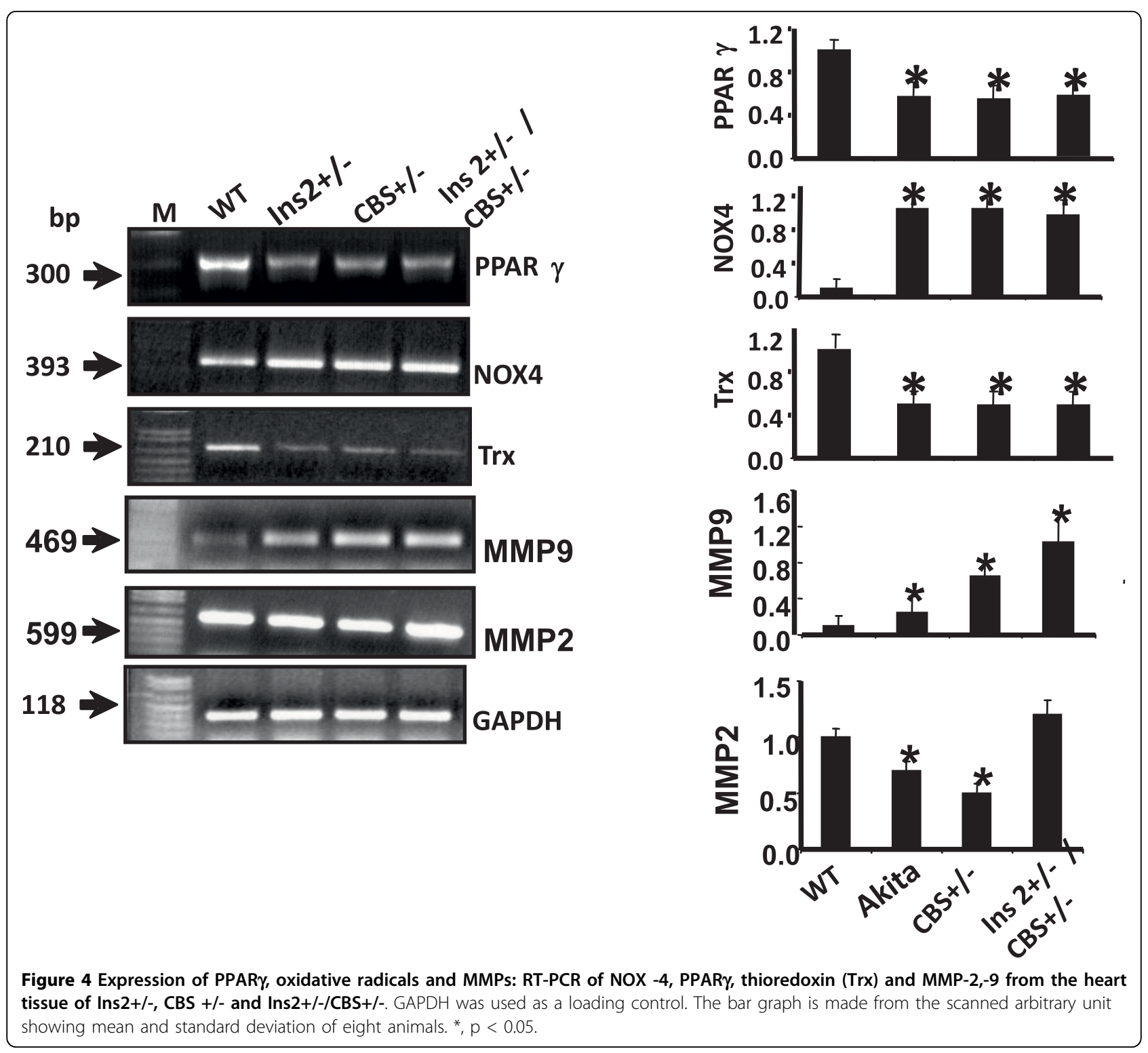

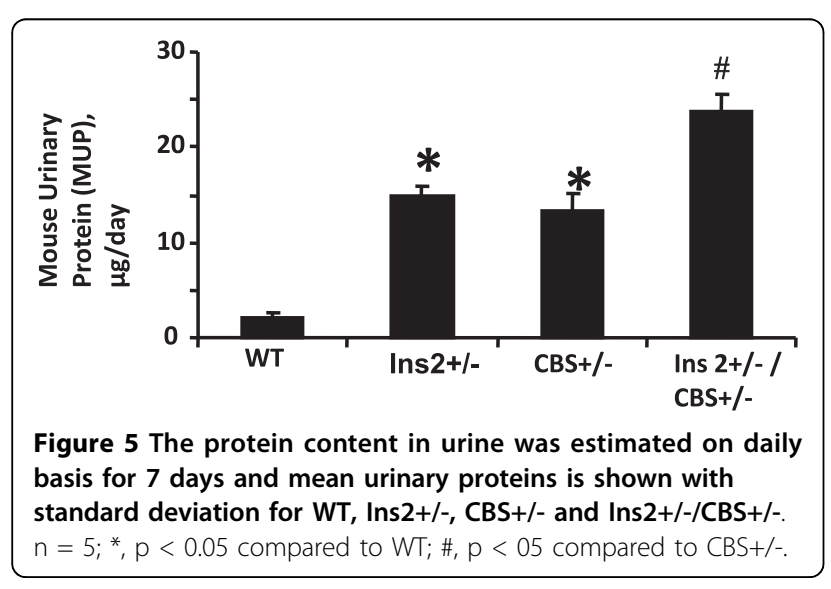

occurs after the developmental age of three to four weeks. Therefore, glucose and Hcy level was determined and compared between WT and Akita at four week. We did not find any significant change in glucose and Hcy level and end diastolic diameter (EDD) at four week in Akita. However, there was robust hyperglycemia and HHcy accompanied by increase in EDD at twenty four week (Figure 1A, B, C). The increase in EDD at twenty four week (Figure 1C) suggests diastolic dysfunction. These results support previous findings of diabetic cardiomyopathy in Akita $[24,25,54,55]$.

Hybrids of Ins2+/- and CBS+/- were confirmed by genotyping (Figure 2). The two-fold increase in glucose and Hcy level in Ins2+/-/CBS+/- suggests synergism in HHcy and hyperglycemia. This finding tempted us to 


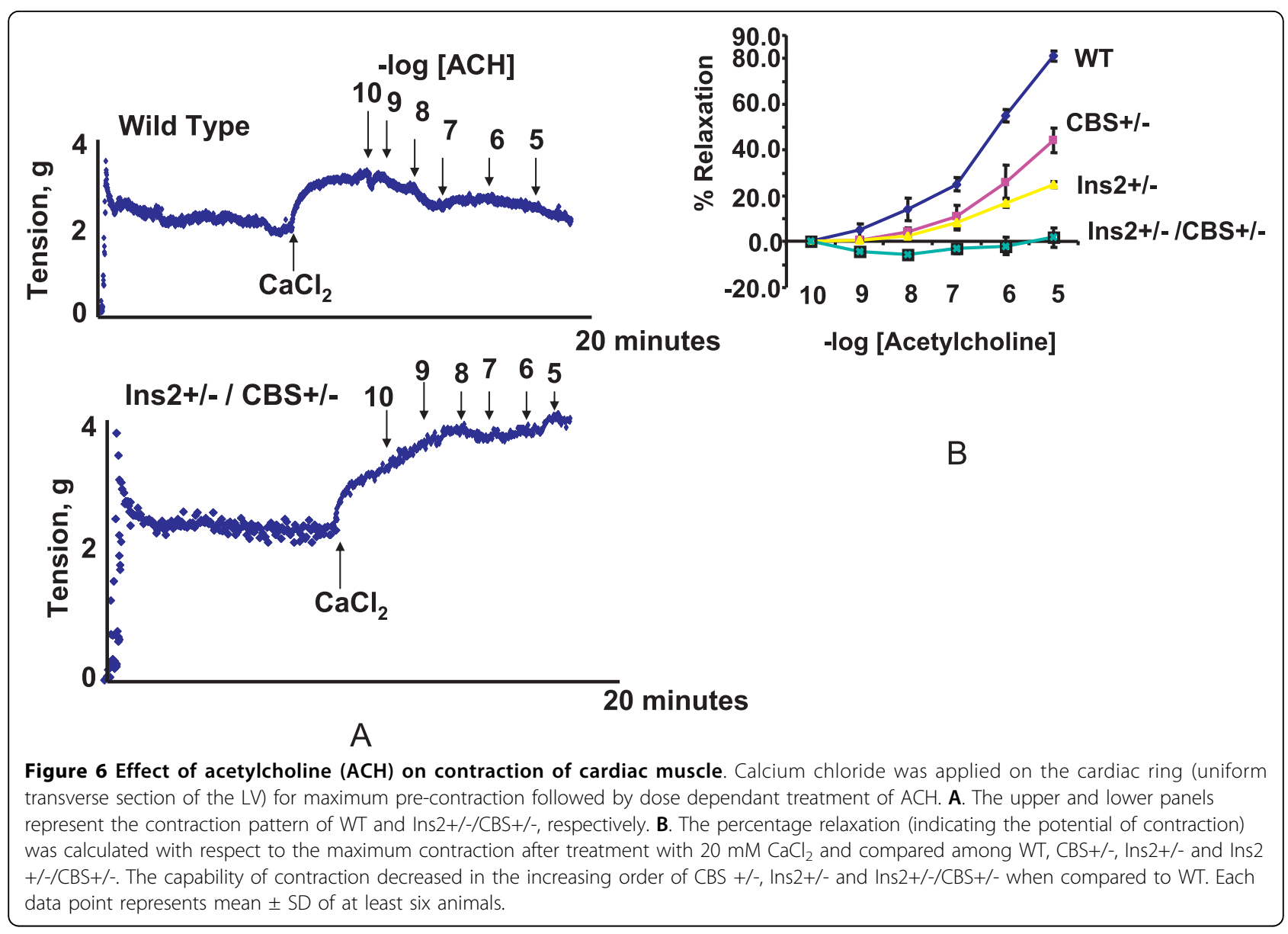

speculate that Ins2 gene might be interfering with Hcy metabolism and inducing hyperhomocysteinemia in CBS $+/$ - (Figure 3). However, further investigations are required to dissect the detailed mechanism. Oxidative

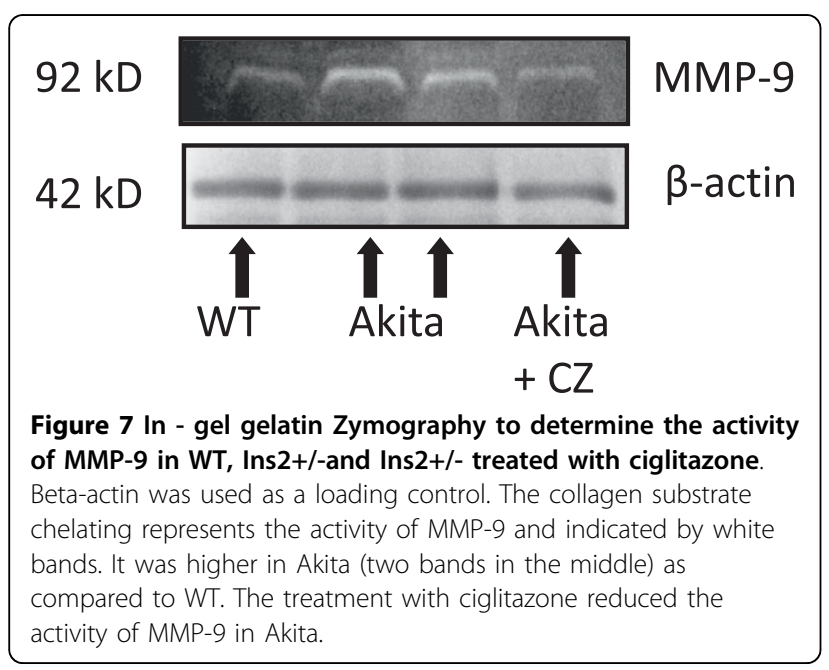

stress generated by HHcy [53] is mitigated by PPAR $\gamma$. The analyses of results (Figure 4) revealed increase in oxidative stress in Ins2+/-, CBS+/- and Ins2+/-/CBS+/as compared to WT due in part to attenuation of PPAR $\gamma$ [41,42]. The increase in oxidative stress in HHcy and diabetic mice extend support to the other published reports $[16-18,43]$. The down regulation of PPAR $\gamma$ in diabetic mice is consistent with the previous finding [21].

Increase in oxidative radicals activates latent MMPs. It is found that MMP-2 and MMP-9 play important role in cardiac remodeling [56-59]. Therefore, we determined the individual and combined effect of hyperglycemia and HHcy on MMP-2 and MMP-9. The results revealed induction of MMP-9 both in Akita and CBS+/-. Interestingly, there was synergism between hyperglycemia and HHcy for MMP-9 induction (Figure 4). MMP-2 was attenuated both in Akita and $\mathrm{CBS}+/-$ but remained unchanged in Ins2+/-/CBS $+/-$ (Figure 4). It indicates that the active site for inducing MMP-2 for either Akita or CBS+/- was antagonized or inhibited in Ins2+/-/CBS $+/$ - . The induction of MMP-9 in HHcy $(\mathrm{CBS}+/-)$ and 


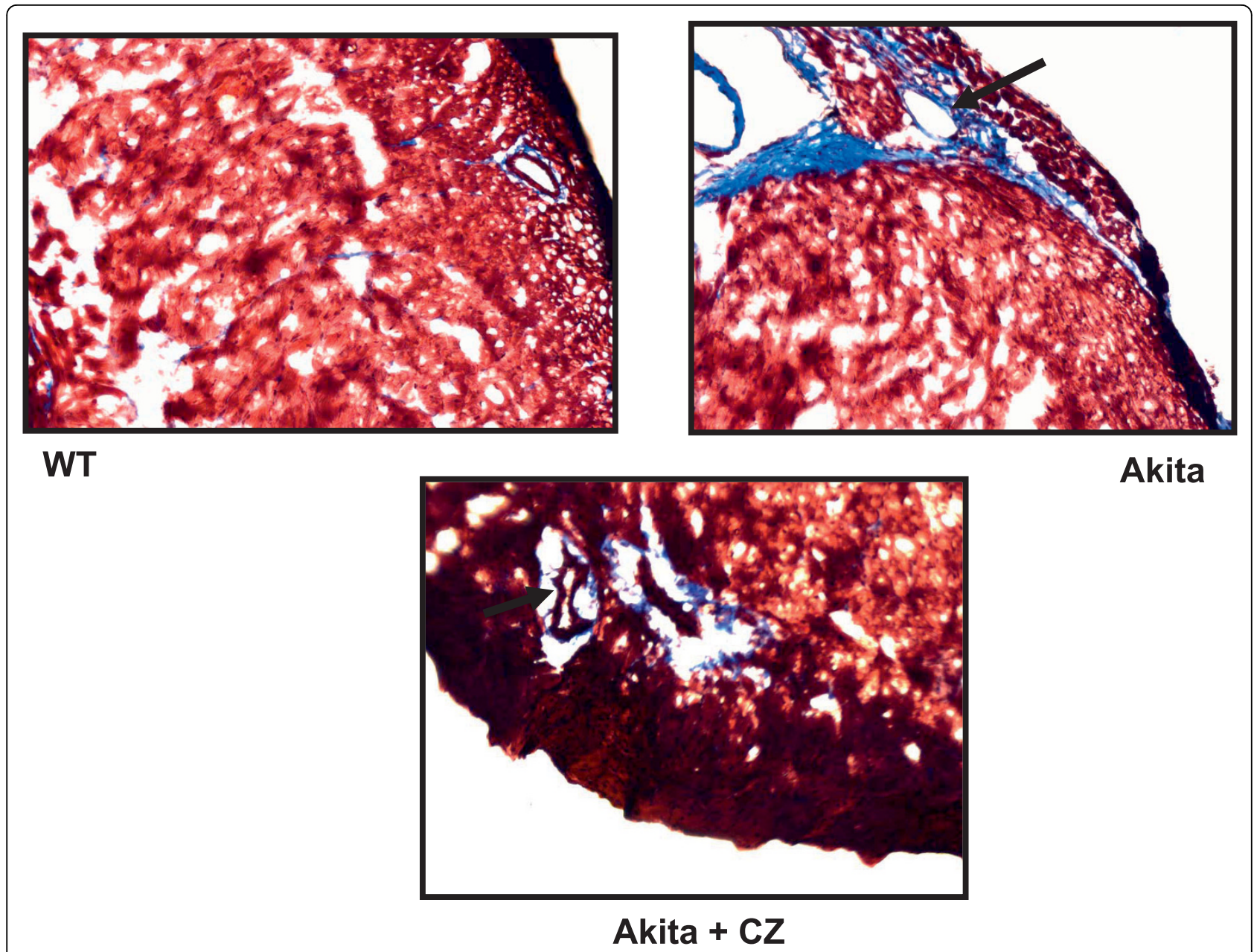

Figure 8 The Masson Trichrome staining of histological sections of the heart from WT, Ins2+/- and Ins2+/- treated with ciglitazone. The blue stain represents collagen deposition. Collagen deposition was increased in Ins2+/- and attenuated after treatment with ciglitazone.

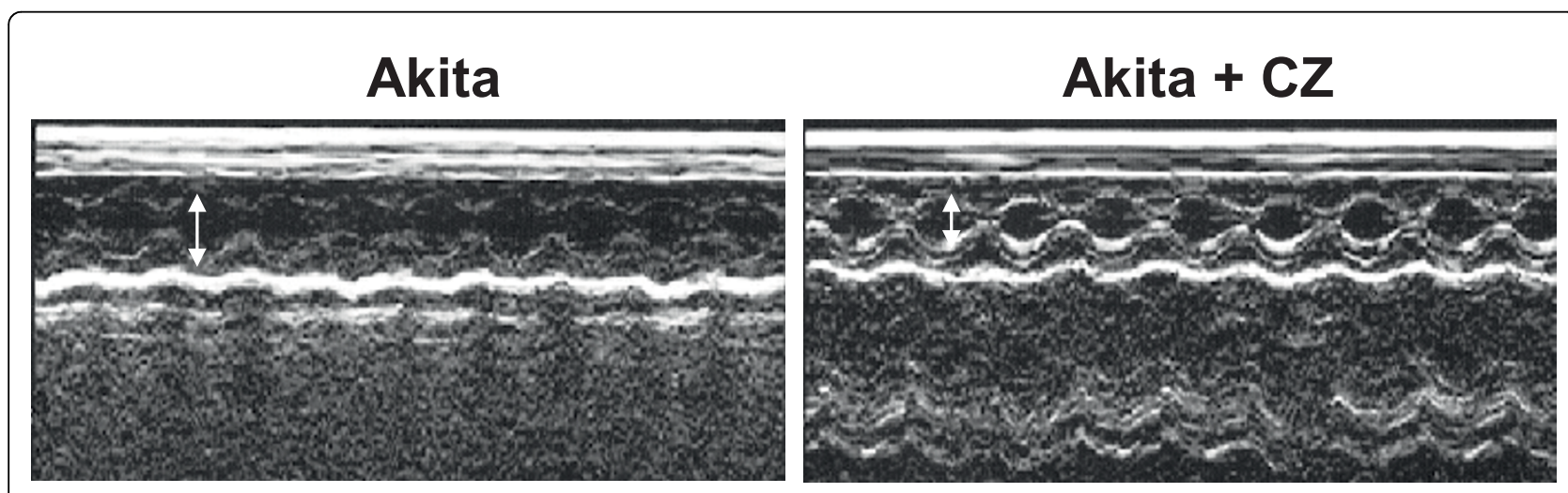

Figure 9 Diastolic diameter of Ins2+/- with and without treatment with ciglitazone. The echocardiogram shows amelioration of diastolic diameter (double headed arrow) of Ins2+/- after treatment with ciglitazone. 


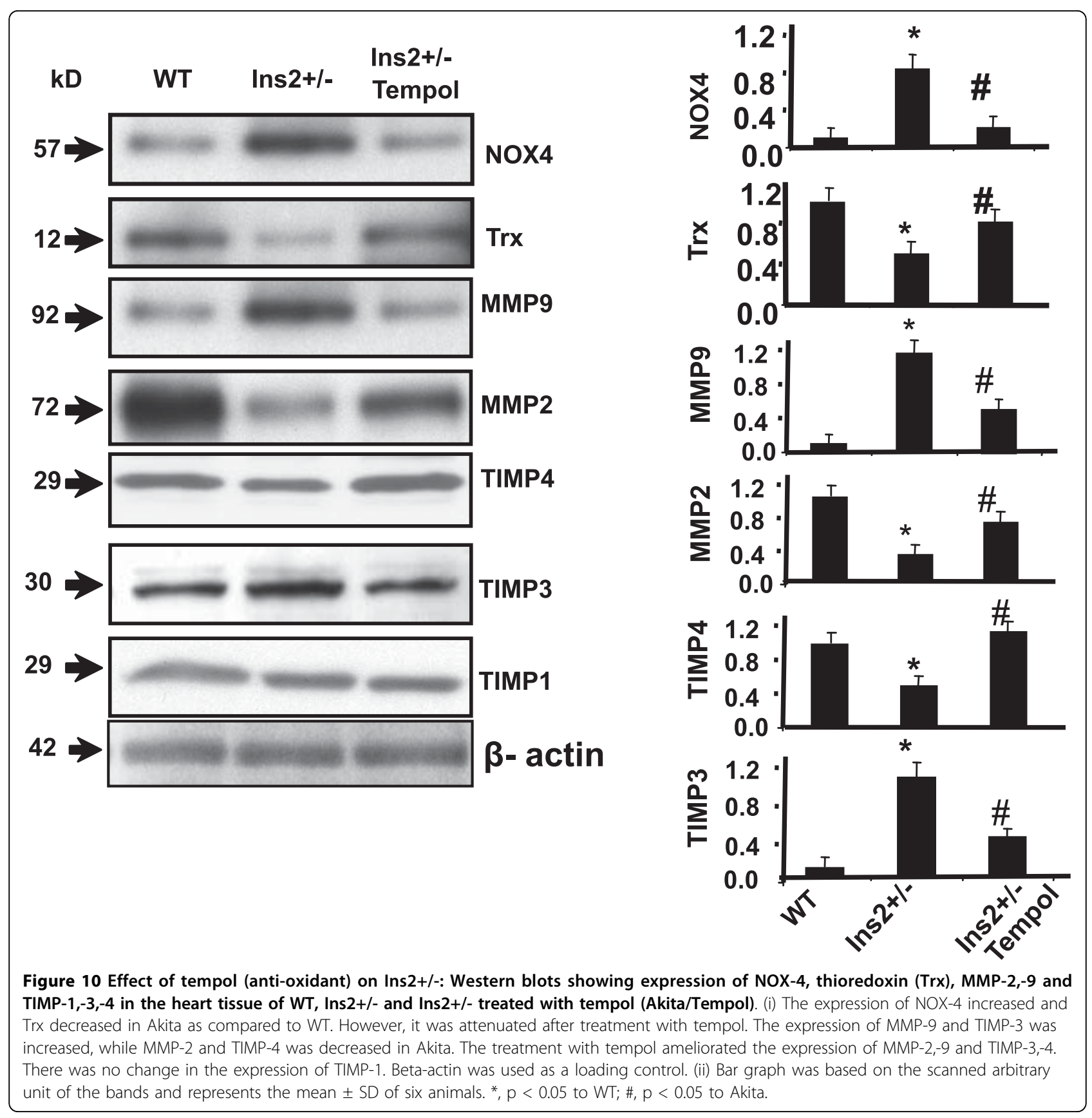

hyperglycemia (Ins2+/-) due to oxidative stress is in line with the earlier findings $[17,20,53,56]$.

Chronic diabetes ultimately leads to multi-organ failure. The alteration in the amount of urinary protein indicates the internal damage of the body [60]. The total urinary protein of twenty four week Akita, $\mathrm{CBS}+/-$ and Ins $2+/-/ C B S+/-$ was compared with WT (Figure 5). We found an increased level of total urinary protein in both Akita and $\mathrm{CBS}+/-$. Interestingly, the total urinary protein was almost two fold increased in Ins $2+/-/ C B S+/-$ suggesting synergistic effect of hyperglycemia and HHcy (Figure 5).

Extracellular matrix bridges endothelium and myocyte, which is essential for maintaining the E-M coupling. The E-M coupling is required for the synchronized beating of cardiomyocytes, and proper systolic contraction and diastolic relaxation of the heart. Defective E-M coupling leads to heart failure. For proper contraction of cardiomyocytes, calcium ion is indispensable. The cardiac rings from the four groups were exposed to $20 \mathrm{mM}$ 


\section{Diabetes Mellitus}

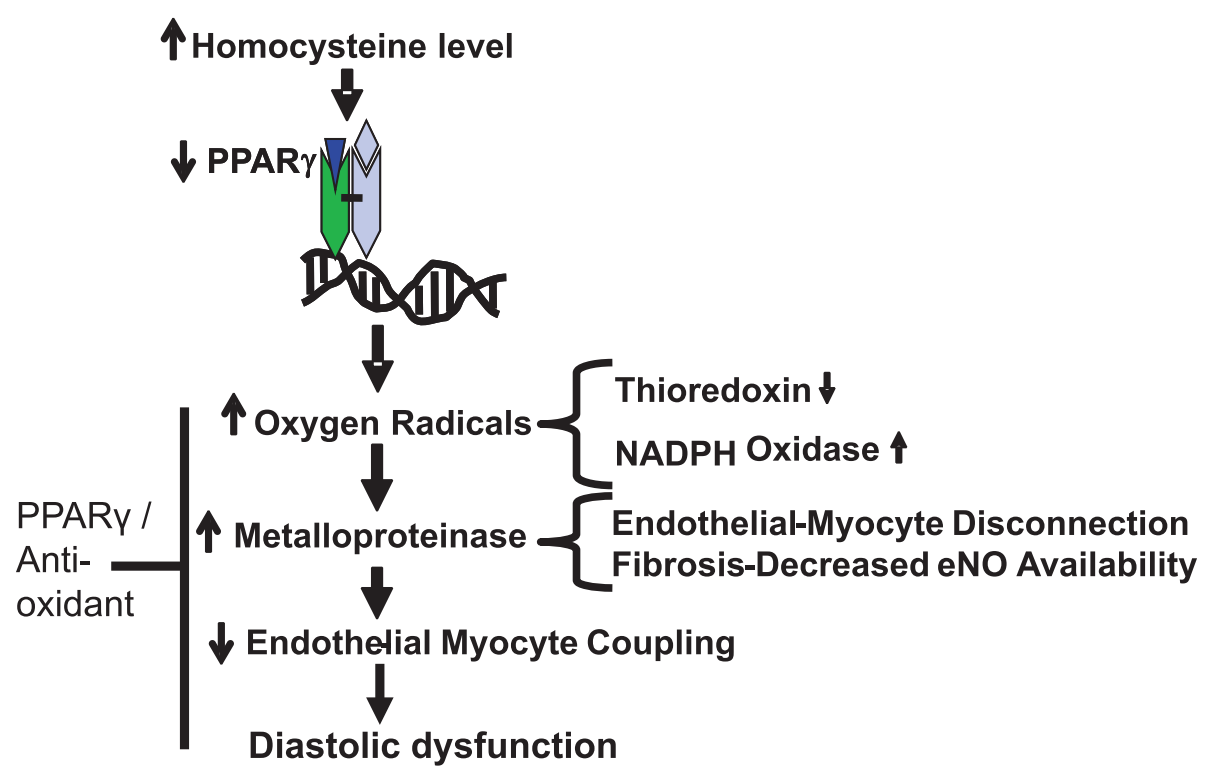

Figure 11 A model for diabetic cardiomyopathy. In diabetes, elevated level of homocysteine induces oxidative radicals by antagonizing PPARy that activates matrix metalloproteinases (MMPs), which in turn causes fibrosis and endothelial-myocytes disconnection. It results into endothelial-myocytes uncoupling that ultimately leads to diastolic dysfunction. PPAR $\gamma$ agonist and anti-oxidants mitigate the effect of oxidative radicals, inhibit the activity of MMPs and thereby ameliorate diastolic dysfunction.

$\mathrm{CaCl}_{2}$ that allows maximum contraction as shown in the representative graph (Figure 6A). After maximum contraction, cardiac rings were exposed to increasing doses of acetylcholine that allows endothelial dependent contraction. The percentage relaxation was recorded from the maximum contraction (Figure 6B). The higher percentage relaxation suggests healthy heart as shown by WT (Figure 6B). We found decrease in the percentage relaxation in $\mathrm{CBS}+/-$ and Akita (Figure 6B). In Ins2 $+/-/ C B S+/-$, there was almost no capacity for relaxation suggesting deterioration of E-M coupling (Figure 6B). These findings reinforce synergism between hyperglycemia and HHcy for E-M uncoupling in Akita. It supports the previous finding that E-M uncoupling is one of the major causes of diabetic cardiomyopathy [21].

To confirm the role of PPAR $\gamma$ in diabetic cardiomyopathy, Akita was treated with CZ- a PPAR $\gamma$ agonist. Since MMP-9 is elevated in Akita (Figure 4) and it causes fibrosis [58], the activity of MMP-9 and level of fibrosis was determined in Akita after treatment with $\mathrm{CZ}$ and compared with WT. In twenty four week Akita, the activity of MMP-9 (Figure 7) and fibrosis (Figure 8) was induced. However, Akita treated with $\mathrm{CZ}$ showed reduced MMP-9 activity and less fibrosis as compared to the untreated group (Figure 7, 8). As PPAR $\gamma$ inhibits the oxidative radicals, it was assumed that the activity of MMP-9 would be inhibited and thereby fibrosis would be ameliorated. The therapeutic effect of $\mathrm{CZ}$ was also confirmed by echocardiography, where EDD was decreased in CZ treated Akita (Figure 9). These findings suggest that PPAR $\gamma$ mitigates the effect of MMP-9 and has cardio-protective role in diabetes. It is consistent with the finding that activation of PPAR $\gamma$ improves endothelial function and thereby mitigates the diabetic cardiomyopathy [30]. Further, PPAR $\gamma$ is also implicated in the modulation of metabolic syndrome that causes cardiovascular complications [30]. The critical role of PPAR $\gamma$ in diabetes and cardiovascular diseases suggest that it can be used as a therapeutic target for diabetic cardiomyopathy.

To investigate the generation of oxidative radicals, the levels of oxidant (NOX-4) and anti-oxidant (Trx) was determined in $\mathrm{WT}$ and Akita. The up regulation of NOX -4 and down regulation of Trx suggests oxidative stress in Akita (Figure 10). TIMP-1 is associated with fibrosis $[58,61,62]$, while TIMP-3 $[58,63]$ is associated with apoptosis. Contrary to our expectation, there was no significant change in the expression of TIMP-1 (Figure 10) suggesting that anti-oxidant tempol does not have direct effect on TIMP-1. However, TIMP-3 was inhibited by tempol (Figure 10) indicating that tempol mitigates apoptosis by inhibiting oxidative radicals. TIMP-4 is abundant in the heart and has cardio-protective role [58]. Tempol treated Akita had attenuated 
expression of NOX-4 and Trx suggesting amelioration of oxidative stress in Akita. The mitigation of cardiomyopathy by tempol is reinforced by attenuation of MMP-9, TIMP-3 and induction of TIMP-4 (Figure 10). It suggests that MMP-9 and TIMP-3, -4 are largely involved in diabetic cardiomyopathy in Akita. These findings support the anti-oxidant effect of tempol [43]. The clinical trails failed to provide any beneficial effect of anti-oxidant treatment (specifically vitamin $\mathrm{C}$ and $\mathrm{E}$ ) for cardiovascular therapy in Heart Outcomes Prevention Evaluation (HOPE), Study to Evaluate Carotid Ultrasound changes in patients treated with Ramipril and vitamin E (SECURE), and Secondary Prevention with Antioxidant of Cardiovascular disease in End stage renal disease (SPACE) [45]. Nonetheless, these trails suffer from several limitations. One of the limitations was that these trials were not designed specifically for assessing the impact of anti-oxidant on diabetes patients. Notably, in specific trial for oxidative stress, where patients on hemodialysis were exposed to high oxidative stress and supplemented with vitamin E showed remarkable response [64] suggesting that anti-oxidant could ameliorate the pathological condition. Although, plethora of evidences supports the anti-oxidant effect of tempol [65-68], hitherto no clinical data is available for its effect on diabetic cardiomyopathy. Our findings extend support to the fact that PPAR $\gamma$ and tempol are promising therapeutic targets for diabetic cardiomyopathy.

Based on our findings, we conclude that in diabetes, HHcy antagonizes PPAR $\gamma$ and induces production of oxygen radicals that enhances MMP-9 and inhibits TIMP-4, which in turn causes matrix remodeling, E-M uncoupling and fibrosis impairing diastolic functions. There is synergism between HHcy and hyperglycemia in diabetic cardiomyopathy. The treatment with PPAR $\gamma$ agonist (CZ) and anti-oxidant (tempol) mitigates oxidative stress and thereby ameliorates diastolic dysfunction in diabetes (Figure 11).

\footnotetext{
Abbreviations

ACH: acetylcholine; CBS: Cystathionine beta synthase; CZ: Ciglitazone; ECM: Extracellular matrix; EDD: End diastolic diameter; E-M: Endothelial- myocyte; Hcy: Homocysteine; HHcy: Hyperhomocysteinemia; HPLC: High- performance liquid chromatography; Ins2: Insulin 2; LV: Left ventricle; LVH: left ventricular hypertrophy; MMP: Matrix metalloproteinase; NOX4: NADPH oxidase 4; PPAR: Peroxisome proliferator- activated receptor; ROS: Reactive oxygen species; SD: standard deviation; TIMP: Tissue inhibitor of metalloproteinase; Trx: Thioredoxin; WT: Wild type.
}

\section{Acknowledgements}

A part of the study was supported by National Institute of Health grants $\mathrm{HL}$ 71010, HL-74185 and HL-88012.

\section{Authors' contributions}

SCT conceived the study. SCT and IGJ designed the study and corrected the manuscript. PKM wrote the manuscript. NT, US and PKM contributed in performing the experiments, analyzing the data and interpreting the results. All authors read and approved the final manuscript.

\section{Competing interests}

The authors declare that they have no competing interests.

Received: 9 August 2010 Accepted: 9 September 2010

Published: 9 September 2010

\section{References}

1. Ciaccio M, Bellia C: Hyperhomocysteinemia and cardiovascular risk: effect of vitamin supplementation in risk reduction. Curr Clin Pharmacol 2010, 5:30-36.

2. Mendez-Gonzalez J, Rodriguez-Millan E, Julve J, Blanco-Vaca F: [Vitamin treatments that lower homocysteine concentration: can they decrease cerebrovascular disease in primary prevention?]. Rev Neurol 2010, 50:235-244.

3. Sen U, Tyagi SC: Homocysteine and Hypertension in Diabetes: Does PPARgamma Have a Regulatory Role? PPAR Res 2010, 2010:806538.

4. Audelin MC, Genest J Jr: Homocysteine and cardiovascular disease in diabetes mellitus. Atherosclerosis 2001, 159:497-511.

5. Dinavahi R, Falkner B: Relationship of homocysteine with cardiovascular disease and blood pressure. J Clin Hypertens (Greenwich) 2004, 6:494-498.

6. Dominguez $L$, Galioto A, Pineo A, Ferlisi A, Ciaccio M, Putignano E, et al: Age, homocysteine, and oxidative stress: relation to hypertension and type 2 diabetes mellitus. J Am Coll Nutr 2010, 29:1-6.

7. Hoogeveen EK, Kostense PJ, Beks PJ, Mackaay AJ, Jakobs C, Bouter LM, et al: Hyperhomocysteinemia is associated with an increased risk of cardiovascular disease, especially in non-insulin-dependent diabetes mellitus: a population-based study. Arterioscler Thromb Vasc Biol 1998, 18:133-138.

8. Hoogeveen EK, Kostense PJ, Jakobs C, Dekker JM, Nijpels G, Heine RJ, et al: Hyperhomocysteinemia increases risk of death, especially in type 2 diabetes: 5-year follow-up of the Hoorn Study. Circulation 2000, 101:1506-1511.

9. Wald DS, Law M, Morris JK: Homocysteine and cardiovascular disease: evidence on causality from a meta-analysis. BMJ 2002, 325:1202.

10. Pavia C, Ferrer I, Valls C, Artuch R, Colome C, Vilaseca MA: Total homocysteine in patients with type 1 diabetes. Diabetes Care 2000, 23:84-87.

11. Homocysteine and risk of ischemic heart disease and stroke: a metaanalysis. JAMA 2002, 288:2015-2022.

12. Carroll JF, Tyagi SC: Extracellular matrix remodeling in the heart of the homocysteinemic obese rabbit. Am J Hypertens 2005, 18:692-698.

13. Singh $A P$, Singh $M$, Balakumar $P$ : Effect of mast cell stabilizers in hyperhomocysteinemia-induced cardiac hypertrophy in rats. J Cardiovasc Pharmacol 2008, 51:596-604.

14. Nosaka S, Murata K, Kobayashi M, Cheng ZB, Maruyama J: Inhibition of baroreflex vagal bradycardia by activation of the rostral ventrolateral medulla in rats. Am J Physiol Heart Circ Physiol 2000, 279:H1239-H1247.

15. Wang $Y$, Jones JF, Jeggo RD, de Burgh DM, Jordan D, Ramage AG: Effect of pulmonary C-fibre afferent stimulation on cardiac vagal neurones in the nucleus ambiguus in anaesthetized cats. J Physiol 2000, 526(Pt 1):157-165.

16. Koz ST, Gouwy NT, Demir N, Nedzvetsky VS, Etem E, Baydas G: Effects of maternal hyperhomocysteinemia induced by methionine intake on oxidative stress and apoptosis in pup rat brain. Int J Dev Neurosci 2010, 28:325-329.

17. Sibrian-Vazquez M, Escobedo JO, Lim S, Samoei GK, Strongin RM: Homocystamides promote free-radical and oxidative damage to proteins. Proc Natl Acad Sci USA 2010, 107:551-554.

18. Solini A, Santini E, Nannipieri M, Ferrannini E: High glucose and homocysteine synergistically affect the metalloproteinases-tissue inhibitors of metalloproteinases pattern, but not TGFB expression, in human fibroblasts. Diabetologia 2006, 49:2499-2506.

19. Solini A, Santini E, Ferrannini E: Effect of short-term folic acid supplementation on insulin sensitivity and inflammatory markers in overweight subjects. Int J Obes (Lond) 2006, 30:1197-1202.

20. Shastry S, Tyagi SC: Homocysteine induces metalloproteinase and shedding of beta-1 integrin in microvessel endothelial cells. J Cell Biochem 2004, 93:207-213. 
21. Rodriguez WE, Sen U, Tyagi N, Kumar M, Carneal G, Aggrawal D, et al: PPAR gamma agonist normalizes glomerular filtration rate, tissue levels of homocysteine, and attenuates endothelial-myocyte uncoupling in alloxan induced diabetic mice. Int J Biol Sci 2008, 4:236-244.

22. Tyagi SC, Hoit BD: Metalloproteinase in myocardial adaptation and maladaptation. J Cardiovasc Pharmacol Ther 2002, 7:241-246.

23. Fallon UB, Elwood P, Ben-Shlomo Y, Ubbink JB, Greenwood R, Smith GD: Homocysteine and ischaemic stroke in men: the Caerphilly study. $J$ Epidemiol Community Health 2001, 55:91-96.

24. Fonseca VA, Fink LM, Kern PA: Insulin sensitivity and plasma homocysteine concentrations in non-diabetic obese and normal weight subjects. Atherosclerosis 2003, 167:105-109.

25. Basu R, Oudit GY, Wang X, Zhang L, Ussher JR, Lopaschuk GD, et al: Type 1 diabetic cardiomyopathy in the Akita (Ins2WT/C96Y) mouse model is characterized by lipotoxicity and diastolic dysfunction with preserved systolic function. Am J Physiol Heart Circ Physiol 2009, 297:H2096-H2108.

26. Ishii I, Akahoshi N, Yamada H, Nakano S, Izumi T, Suematsu M: Cystathionine \{gamma\}-lyase-deficient mice require dietary cysteine to protect against acute lethal myopathy and oxidative injury. $J \mathrm{Biol}$ Chem 2010, 20;285(34):26358-68, Epub 2010 Jun 21.

27. Sen U, Munjal C, Qipshidze N, Abe O, Gargoum R, Tyagi SC: Hydrogen sulfide regulates homocysteine-mediated glomerulosclerosis. Am J Nephrol 2010, 31:442-455.

28. Tyagi N, Mishra PK, Tyagi SC: Homocysteine, hydrogen sulfide (H2S) and NMDA-receptor in heart failure. Indian J Biochem Biophys 2009, 46:441-446.

29. Tyagi N, Givvimani S, Qipshidze N, Kundu S, Kapoor S, Vacek JC, et al: Hydrogen sulfide mitigates matrix metalloproteinase- 9 activity and neurovascular permeability in hyperhomocysteinemic mice. Neurochem Int 2010, 56:301-307.

30. Tenenbaum A, Fisman EZ, Motro M: Metabolic syndrome and type 2 diabetes mellitus: focus on peroxisome proliferator activated receptors (PPAR). Cardiovasc Diabetol 2003, 2:4.

31. Folmes CD, Clanachan AS, Lopaschuk GD: Fatty acid oxidation inhibitors in the management of chronic complications of atherosclerosis. Curr Atheroscler Rep 2005, 7:63-70.

32. Nolte RT, Wisely GB, Westin S, Cobb JE, Lambert MH, Kurokawa R, et al: Ligand binding and co-activator assembly of the peroxisome proliferator-activated receptor-gamma. Nature 1998, 395:137-143.

33. Itoh H, Doi K, Tanaka T, Fukunaga $Y$, Hosoda $K$, Inoue G, et al: Hypertension and insulin resistance: role of peroxisome proliferator-activated receptor gamma. Clin Exp Pharmacol Physiol 1999, 26:558-560.

34. Lebovitz HE, Banerji MA: Insulin resistance and its treatment by thiazolidinediones. Recent Prog Horm Res 2001, 56:265-294.

35. Marx N, Sukhova G, Murphy C, Libby P, Plutzky J: Macrophages in human atheroma contain PPARgamma: differentiation-dependent peroxisomal proliferator-activated receptor gamma(PPARgamma) expression and reduction of MMP-9 activity through PPARgamma activation in mononuclear phagocytes in vitro. Am J Pathol 1998, 153:17-23.

36. Bissonnette R, Treacy E, Rozen R, Boucher B, Cohn JS, Genest J Jr: Fenofibrate raises plasma homocysteine levels in the fasted and fed states. Atherosclerosis 2001, 155:455-462.

37. Blane GF: Comparative toxicity and safety profile of fenofibrate and other fibric acid derivatives. Am J Med 1987, 83:26-36.

38. Dierkes J, Westphal S, Luley C: Serum homocysteine increases after therapy with fenofibrate or bezafibrate. Lancet 1999, 354:219-220.

39. Brude IR, Finstad HS, Seljeflot I, Drevon CA, Solvoll K, Sandstad B, et al: Plasma homocysteine concentration related to diet, endothelial function and mononuclear cell gene expression among male hyperlipidaemic smokers. Eur J Clin Invest 1999, 29:100-108.

40. Barger PM, Brandt JM, Leone TC, Weinheimer CJ, Kelly DP: Deactivation of peroxisome proliferator-activated receptor-alpha during cardiac hypertrophic growth. J Clin Invest 2000, 105:1723-1730.

41. Hunt MJ, Tyagi SC: Peroxisome proliferators compete and ameliorate Hcy-mediated endocardial endothelial cell activation. Am J Physiol Cell Physiol 2002, 283:C1073-C1079.

42. Yamamoto K, Ohki R, Lee RT, Ikeda U, Shimada K: Peroxisome proliferatoractivated receptor gamma activators inhibit cardiac hypertrophy in cardiac myocytes. Circulation 2001, 104:1670-1675.

43. Jagadeesha DK, Lindley TE, Deleon J, Sharma RV, Miller F, Bhalla RC: Tempol therapy attenuates medial smooth muscle cell apoptosis and neointima formation after balloon catheter injury in carotid artery of diabetic rats. Am J Physiol Heart Circ Physiol 2005, 289:H1047-H1053.

44. Viswanad B, Srinivasan $\mathrm{K}$, Kaul CL, Ramarao P: Effect of tempol on altered angiotensin II and acetylcholine-mediated vascular responses in thoracic aorta isolated from rats with insulin resistance. Pharmacol Res 2006, 53:209-215.

45. Johansen JS, Harris AK, Rychly DJ, Ergul A: Oxidative stress and the use of antioxidants in diabetes: linking basic science to clinical practice. Cardiovasc Diabetol 2005, 4:5.

46. Watanabe M, Osada J, Aratani Y, Kluckman K, Reddick R, Malinow MR, et al: Mice deficient in cystathionine beta-synthase: animal models for mild and severe homocyst(e)inemia. Proc Natl Acad Sci USA 1995, 92:1585-1589.

47. Sivarajah A, McDonald MC, Thiemermann C: The cardioprotective effects of preconditioning with endotoxin, but not ischemia, are abolished by a peroxisome proliferator-activated receptor-gamma antagonist. J Pharmacol Exp Ther 2005, 313:896-901.

48. Evans M, Anderson RA, Graham J, Ellis GR, Morris K, Davies S, et al: Ciprofibrate therapy improves endothelial function and reduces postprandial lipemia and oxidative stress in type 2 diabetes mellitus. Circulation 2000, 101:1773-1779.

49. Scatena R, Bottoni P, Giardina B: Mitochondria, PPARs, and Cancer: Is Receptor-Independent Action of PPAR Agonists a Key? PPAR Res 2008, 2008:256251.

50. Guo L, Zhang L, Sun Y, Muskhelishvili L, Blann E, Dial S, et al: Differences in hepatotoxicity and gene expression profiles by anti-diabetic PPAR gamma agonists on rat primary hepatocytes and human HepG2 cells. Mol Divers 2006, 10:349-360.

51. Sen U, Tyagi N, Kumar M, Moshal KS, Rodriguez WE, Tyagi SC: Cystathionine-beta-synthase gene transfer and 3-deazaadenosine ameliorate inflammatory response in endothelial cells. Am J Physiol Cell Physiol 2007, 293:C1779-C1787.

52. Tyagi SC, Smiley LM, Mujumdar VS: Homocyst(e)ine impairs endocardial endothelial function. Can J Physiol Pharmacol 1999, 77:950-957.

53. Mishra PK, Tyagi N, Kundu S, Tyagi SC: MicroRNAs are involved in homocysteine-induced cardiac remodeling. Cell Biochem Biophys 2009, 55:153-162.

54. Garin I, Edghill EL, Akerman I, Rubio-Cabezas O, Rica I, Locke JM, et al: Recessive mutations in the INS gene result in neonatal diabetes through reduced insulin biosynthesis. Proc Natl Acad Sci USA 2010, 107:3105-3110.

55. Hong EG, Jung DY, Ko HJ, Zhang Z, Ma Z, Jun JY, et al: Nonobese, insulindeficient Ins2Akita mice develop type 2 diabetes phenotypes including insulin resistance and cardiac remodeling. Am J Physiol Endocrinol Metab 2007, 293:E1687-E1696.

56. Adamcova M, Potacova A, Popelova O, Sterba M, Mazurova Y, Aupperle H, et al: Cardiac remodeling and MMPs on the model of chronic daunorubicin-induced cardiomyopathy in rabbits. Physiol Res 2010.

57. Awad AE, Kandalam V, Chakrabarti S, Wang X, Penninger JM, Davidge ST, et al: Tumor necrosis factor induces matrix metalloproteinases in cardiomyocytes and cardiofibroblasts differentially via superoxide production in a PI3Kgamma-dependent manner. Am J Physiol Cell Physiol 2010, 298:C679-C692.

58. Mishra PK, Tyagi N, Sen U, Givvimani S, Tyagi SC: H2 S ameliorates oxidative and proteolytic stresses and protects the heart against adverse remodeling in chronic heart failure. Am J Physiol Heart Circ Physiol 2010, 298:H451-H456.

59. Okada M, Yamawaki H, Hara Y: Angiotensin II enhances interleukin-1 beta-induced MMP-9 secretion in adult rat cardiac fibroblasts. J Vet Med Sci 2010, 72:735-739.

60. Maheshwari A, Singh AK, Sinha DK, Tripathi K, Prakash J: Spectrum of renal disease in malaria. J Indian Med Assoc 2004, 102:143, 146, 148.

61. Gonzalez A, Lopez B, Querejeta R, Zubillaga E, Echeverria T, Diez J: Filling pressures and collagen metabolism in hypertensive patients with heart failure and normal ejection fraction. Hypertension 2010, 55:1418-1424.

62. Gramley F, Lorenzen J, Knackstedt C, Rana OR, Saygili E, Frechen D, et al: Age-related atrial fibrosis. Age (Dordr) 2009, 31:27-38.

63. Johnson JL, Sala-Newby GB, Ismail Y, Aguilera CM, Newby AC: Low tissue inhibitor of metalloproteinases 3 and high matrix metalloproteinase 14 levels defines a subpopulation of highly invasive foam-cell macrophages. Arterioscler Thromb Vasc Biol 2008, 28:1647-1653.

64. Boaz M, Smetana S, Weinstein T, Matas Z, Gafter U, laina A, et al: Secondary prevention with antioxidants of cardiovascular disease in endstage renal 
disease (SPACE): randomised placebo-controlled trial. Lancet 2000,

356:1213-1218

65. Bell D, Zhao Y, McCoy FP, Devine AB, McDermott BJ: Differential effects of an anti-oxidant intervention on cardiomyocyte expression of adrenomedullin and intermedin and their receptor components in chronic nitric oxide deficiency. Cell Physiol Biochem 2007, 20:269-282.

66. Hahn SM, Mitchell JB, Shacter E: Tempol inhibits neutrophil and hydrogen peroxide-mediated DNA damage. Free Radic Biol Med 1997, 23:879-884.

67. Rippe C, Lesniewski L, Connell M, LaRocca T, Donato A, Seals D: Short-term calorie restriction reverses vascular endothelial dysfunction in old mice by increasing nitric oxide and reducing oxidative stress. Aging Cell 2010 9:304-312.

68. Zhang $Y$, Jang R, Mori TA, Croft KD, Schyvens CG, McKenzie KU, et al: The anti-oxidant Tempol reverses and partially prevents adrenocorticotrophic hormone-induced hypertension in the rat. $J$ Hypertens 2003, 21:1513-1518.

doi:10.1186/1475-2840-9-49

Cite this article as: Mishra et al: Synergism in hyperhomocysteinemia and diabetes: role of PPAR gamma and tempol. Cardiovascular Diabetology 2010 9:49.

\section{Submit your next manuscript to BioMed Central} and take full advantage of:

- Convenient online submission

- Thorough peer review

- No space constraints or color figure charges

- Immediate publication on acceptance

- Inclusion in PubMed, CAS, Scopus and Google Scholar

- Research which is freely available for redistribution

Submit your manuscript at www.biomedcentral.com/submit 